\title{
Fluoranthene metabolism in Mycobacterium sp. strain KR20: identity of pathway intermediates during degradation and growth
}

\author{
Klaus Rehmann, ${ }^{1,2}$ Norbert Hertkorn ${ }^{1}$ and Antonius A. Kettrup ${ }^{1,2}$ \\ Author for correspondence: Klaus Rehmann. Tel: +49 89 31872514. Fax: + 498931873372. \\ e-mail: rehmann@gsf.de
}

1 GSF - National Research Center for Environment and Health, Institute of Ecological Chemistry, Ingolstädter Landstraße 1, D-85764 Neuherberg, Germany

2 Technical University Munich, Chair of Ecological Chemistry and Environmental Analytics, D-85350 Freising, Germany

\begin{abstract}
Mycobacterium sp. strain KR20, which was isolated from a polycyclic aromatic hydrocarbon (PAH) contaminated soil of a former gaswork plant site, metabolized about $60 \%$ of the fluoranthene added $\left(0.5 \mathrm{mg} \mathrm{ml}^{-1}\right)$ to batch cultures in mineral salts medium within $10 \mathrm{~d}$ at $20^{\circ} \mathrm{C}$. It thereby increased its cell number about 30-fold and produced at least seven metabolites. Five metabolites, namely cis-2,3-fluoranthene dihydrodiol, Z-9-carboxymethylenefluorene-1-carboxylic acid, cis-1,9a-dihydroxy-1-hydro-fluorene-9-one-8carboxylic acid, 4-hydroxybenzochromene-6-one-7-carboxylic acid and benzene1,2,3-tricarboxylic acid, could be identified by NMR and MS spectroscopic techniques and ascribed to an alternative fluoranthene degradation pathway. Besides fluoranthene, the isolate could not use any of the PAHs tested as a sole source of carbon and energy.
\end{abstract}

Keywords: biodegradation, degradation products, degradation pathway, polycyclic aromatic hydrocarbons, ring cleavage

\section{INTRODUCTION}

Polycyclic aromatic hydrocarbons (PAHs) are ubiquitous environmental contaminants, well known for their mutagenic and carcinogenic properties (Edwards, 1983; Harvey, 1991; Suess, 1976). Soil areas heavily contaminated by these compounds, such as former carbonizing plant or gasworks sites, need a proper clean-up prior to future human use and thus are major targets for the application of microbiological remediation techniques (Thomas \& Lester, 1993, 1994).

During the last 15 years it has become evident that PAHs with more than three rings, despite their low water solubility, may serve as growth substrates for a number of soil bacteria. However, our knowledge of microbial transformation capabilities for PAHs with more than three rings is still limited (Kanaly \& Harayama, 2000; Sutherland et al., 1995). The utilization of fluoranthene as a sole source of carbon and energy by a pure bacterial strain was first described by Weißenfels et al. (1990) and Mueller et al. (1990). Despite the

\footnotetext{
Abbreviations: COSY, correlated spectroscopy; HMBC, heteronuclear multiple bond correlation; HMQC, heteronuclear multiple quantum correlation; LC, liquid chromatography; MSTFA, $N$-methyl- $N$-(trimethylsilyl) trifluoroacetamide; NOESY, nuclear Overhauser and exchange spectroscopy; PAH, polycyclic aromatic hydrocarbon; TMS, trimethylsilyl; UV-Vis, UV-visible.
}

description of several other fluoranthene-utilizing strains (Boldrin et al., 1993; Bouchez et al., 1995; Bryniok, 1994; Dagher et al., 1997; Ho et al., 2000; Juhasz et al., 1997; Kästner et al., 1994; Kleespies et al., 1996; Lloyd-Jones \& Hunter, 1997; Mueller et al., 1997; Sepic et al., 1998; Thibault et al., 1996; Walter et al., 1991; Willumsen et al., 1998), data on initial metabolites are relatively scarce.

In this study we investigated the fluoranthene-degrading capability of Mycobacterium sp. strain KR20 (Rehmann et al., 1999), presenting information on the time course of fluoranthene degradation as well as detailed structural data of several metabolites. We discuss the implication of our results with respect to our current understanding of the bacterial degradation of fluoranthene, focussing on the degradation pathways known to date.

\section{METHODS}

Chemicals. Inorganic chemicals and solvents (analytical and chromatography grades, respectively) were purchased from Merck. Organic chemicals of the highest purity available were from Aldrich. Difco Bactoagar was obtained from BD GmbH, and $N$-methyl-N-(trimethylsilyl) trifluoroacetamide (MSTFA) used for GC-MS derivatization was from Macherey-Nagel.

Isolation and characterization of the organism. A fluoranthene-degrading mixed culture was enriched from a PAHcontaminated soil (former gasworks site, Kassel, Germany) 
using a mineral salts medium (MSM) (Weißenfels et al., 1990) with fluoranthene added as the sole source of carbon and energy (see below). A suspected fluoranthene-utilizing member of this bacterial community was identified by its ability to produce clear zones on fluoranthene-coated MSM agar plates (Kiyohara et al., 1982) and isolated by conventional microbial techniques. It was preliminarily characterized by Gram and acid-fast staining. The mycolic acid pattern of the isolate was determined using the TLC method of Minnikin et al. (1975). Utilization of PAHs other than fluoranthene and of Tween 80 was studied in liquid media containing $0.5 \mathrm{mg} \mathrm{ml}^{-1}$ of the respective substrate and inoculated with MSM-washed KR2 0 cells pre-grown in R2A medium (Reasoner \& Geldreich, 1985). R2A agar plates $(20 \mathrm{ml})$ used in colony-forming units (c.f.u.) plate-counting experiments were incubated at $25^{\circ} \mathrm{C}$.

Cultivation of Mycobacterium sp. strain KR20. Standard cultivation conditions were as described by Rehmann et al. (1998) in the presence of a nominal concentration of $0.5 \mathrm{mg}$ fluoranthene $\mathrm{ml}^{-1}$. All cultures were incubated on a rotary shaker at $20^{\circ} \mathrm{C}$ and 100 r.p.m. The optical density of $10 \mathrm{ml}$ cultures was determined at $578 \mathrm{~nm}$ using a UVICAM 5675 spectrophotometer by means of tube-connected cuvettes (diameter $10 \mathrm{~mm}$ ), which were mounted onto the screw caps of the culture vessels. Starter cultures $(10 \mathrm{ml})$ were inoculated from R2A agar slants. After reaching an $\mathrm{OD}_{578}$ of $0.3-0.5$ these cultures served as an inoculant $(10 \%, \mathrm{v} / \mathrm{v})$ for new $10 \mathrm{ml}$ or $100 \mathrm{ml}$ cultures. Medium-term maintenance of the strain (up to 3 months) was performed on R2A agar slants which, after confluent growth had appeared, were stored at $4{ }^{\circ} \mathrm{C}$, whereas $-80^{\circ} \mathrm{C}$ deep-frozen suspensions of R2A-agar grown cells in $50 \%(\mathrm{w} / \mathrm{v})$ glycerol were used for long-term storage.

Chromatographic analysis, preparation and identification of fluoranthene metabolites. Sample preparation for quantitative HPLC analysis was performed as described by Rehmann et al. (1998). Ethyl acetate extracts prepared from acidified ( $\mathrm{pH} 1 \cdot 5,1 \mathrm{M} \mathrm{HCl}) 10 \mathrm{ml}$ whole cultures were dried over anhydrous $\mathrm{Na}_{2} \mathrm{SO}_{4}$. The solvent was removed under reduced pressure and the residues dissolved in a suitable volume of methanol. Samples were analysed by HPLC (HP1090, Hewlett Packard) applying UV-Vis diode array detection and using a Baker Widebore RP18 column (J. T. Baker Inc.) at $40^{\circ} \mathrm{C}$. Fluoranthene determination was performed isocratically using a methanol $/ 8 \mathrm{mM}$ phosphoric acid $85: 15(\mathrm{v} / \mathrm{v})$ mixture at a flow of $0.8 \mathrm{ml} \mathrm{min}{ }^{-1}$, applying a detection wavelength of $235 \mathrm{~nm}$. Metabolite separation was achieved in a linear $8 \mathrm{mM}$ phosphoric acid/methanol gradient : $0 \%$ to $100 \%$ methanol within $30 \mathrm{~min}$ at a flow of $0.8 \mathrm{ml} \mathrm{min}{ }^{-1}$. Metabolites were detected at $235 \mathrm{~nm}$ and $254 \mathrm{~nm}$. UV-Vis spectra were recorded at the peak maxima and were corrected for solvent background. The recovery of fluoranthene under the extraction conditions described was $>85 \%$ down to a concentration of $5 \mu \mathrm{g} \mathrm{ml}^{-1}$.

For the purification of metabolites, eight samples of 5- to 8 -d-old $100 \mathrm{ml}$ cultures were filtered through glass wool to remove residual fluoranthene crystals. Combined filtrates were extracted three times with $250 \mathrm{ml}$ ethyl acetate to separate excess fluoranthene and non-dissociating metabolites. The filtrates (aqueous phases) were subsequently acidified ( $\mathrm{pH} 1 \cdot 5$, $1 \mathrm{M} \mathrm{HCl}$ ) and subjected to a second threefold ethyl acetate extraction. Corresponding extracts were pooled, dried over anhydrous $\mathrm{Na}_{2} \mathrm{SO}_{4}$ and the solvent was removed under reduced pressure at $35^{\circ} \mathrm{C}$. Extraction residues dissolved in a suitable volume of methanol were fractionated by liquid chromatography (LC) (Merck-Hitachi: pump L6200, autosampler AS2000A, UV-Vis detector L4000, Merck) at room temperature on an RP18 column $(250 \times 10 \mathrm{~mm}$, Merck Lichroprep, Merck). Selected mixtures (composition depending on the respective metabolite) of methanol and acetic acid $(4 \%, v / v)$, followed by pure methanol, served to separate the constituents of the acidic extract at a flow of $2 \mathrm{ml} \mathrm{min}$. For the purification of the constituents of the neutral extract, acetic acid was replaced by water. Fractions were collected according to the UV-absorbance profile of the eluates at $235 \mathrm{~nm}$ or $254 \mathrm{~nm}$. The solvent was removed (see above) and the metabolites were redissolved in methanol. Metabolite I was further purified by TLC on silica gel plates $\left(60 \mathrm{~F}_{254}, 200 \times 200 \mathrm{~mm}\right.$, thickness $0.25 \mathrm{~mm}$, Merck) in an ethyl acetate/methanol $8: 2$ solvent system. The purity of the metabolites was routinely checked by HPLC and was finally $\geqslant 90 \%$.

${ }^{1} \mathrm{H}$ - and 2D-NMR spectra were recorded with a Bruker DMX 500 spectrometer using Bruker standard software (Bruker Analytik; proton frequency $500 \cdot 13 \mathrm{MHz}$ ) employing $2.0 \mathrm{~mm}$ capillaries and an inverse-geometry TXI $2.5 \mathrm{~mm}$ probehead $\left(90^{\circ}: 9.4 \mu \mathrm{s}{ }^{1} \mathrm{H} ; 10 \cdot 0 \mu \mathrm{s}{ }^{13} \mathrm{C}\right)$ in methanol- $d_{4}$, acetone- $d_{6}$ and chloroform- $d_{1}$, respectively, at $30{ }^{\circ} \mathrm{C}\left({ }^{1} \mathrm{H} /{ }^{13} \mathrm{C}: 3 \cdot 30 / 49 \cdot 00\right.$, $2 \cdot 04 / 29 \cdot 00$ and $7 \cdot 24 / 77 \cdot 00$ p.p.m.). ${ }^{1} \mathrm{H},{ }^{13} \mathrm{C}-\mathrm{HMBC}$ (heteronuclear multiple bond correlation) spectra to determine the position of carbons without directly bonded protons were recorded in the absolute-value mode F1: $6800 \mathrm{~Hz}$, using coupling constants of $10 \mathrm{~Hz}$ (metabolites I, IV), and 5, 7·5, 10 and $15 \mathrm{~Hz}$ (metabolite III). ${ }^{1} \mathrm{H},{ }^{13} \mathrm{C}-\mathrm{HMQC}$ (heteronuclear multiple quantum correlation) spectra to assign carbons bearing a proton were acquired by use of BIRD (bilinear rotation decoupling) pulses and ${ }^{13} \mathrm{C}$-GARP (globally optimized alternating-phase rectangular pulses) decoupling [BIRD: $500 \mathrm{~ms}$, GARP: $70 \mu \mathrm{s}$, aq: $95-320 \mathrm{~ms}$, sw (F2): $5400 \mathrm{~Hz}, \mathrm{~d} 1: 1 \cdot 5-2 \cdot 5 \mathrm{~s},{ }^{1} J(\mathrm{CH}): 145 \mathrm{~Hz}$ (metabolite II), $160 \mathrm{~Hz}$ (metabolites I, III, IV), number of increments in F1: 60-256]. The ${ }^{13} \mathrm{C}-\mathrm{NMR}$ spectra were recorded with a $2.5 \mathrm{~mm}$ dual probehead $\left(90^{\circ}: 9 \cdot 0 \mu \mathrm{s}\right)$ with broad-band decoupling and an acquisition time of 1.0-1.9 s (relaxation delay $\mathrm{d} 1: 3.5-5 \mathrm{~s}$ ).

Absolute-value DQ- ${ }^{1} \mathrm{H},{ }^{1} \mathrm{H}$-COSY (double-quantum ${ }^{1} \mathrm{H},{ }^{1} \mathrm{H}$ correlated spectroscopy) spectra (aq: $200 \mathrm{~ms}$ ) were acquired on a Bruker AC 400 NMR spectrometer (Bruker Analytik, proton frequency: $400 \cdot 13 \mathrm{MHz}$ ) using an inverse-geometry $5 \mathrm{~mm}$ probehead $\left(90^{\circ}: 8 \cdot 0 \mu \mathrm{s}\right)$. Phase-sensitive TPPI (timeproportional phase increment) ${ }^{1} \mathrm{H},{ }^{1} \mathrm{H}-\mathrm{NOESY}$ (nuclear Overhauser and exchange spectroscopy) spectra were recorded on the same instrument with mixing times of $800 \mathrm{~ms}$ (metabolites III, V) and $650 \mathrm{~ms}$ (metabolite IV). COSY and NOESY spectra served to establish the succession of protons in metabolites II, III, IV and V.

For GC-MS (capillary column gas chromatography-mass spectrometry) analysis, trimethylsilyl (TMS) derivatives of the metabolites were prepared according to Zink \& Lorber (1995). The analysis was performed in the EI mode $(70 \mathrm{eV})$ on an HP 5890 series II chromatograph (Hewlett Packard) equipped with a DB5 capillary column, $0.25 \mathrm{~mm}$ inside diameter by $60 \mathrm{~m}$, coating $0 \cdot 1 \mu \mathrm{m}$, coupled to a Finnigan Mat SSQ 7000 quadrupole spectrometer (Finnigan MAT GmbH). Samples were injected into the $\mathrm{GC}$ at $90^{\circ} \mathrm{C}$, held isothermally for $1 \mathrm{~min}$, programmed to $270{ }^{\circ} \mathrm{C}$ at $15^{\circ} \mathrm{C} \mathrm{min}{ }^{-1}$, and held isothermally for another $20 \mathrm{~min}$. A similar method was successfully applied for the analysis of bacterial fluoranthene metabolites by Sepic et al. (1998) and Sepic \& Leskovsek (1999).

Direct-infusion LC-MS was performed on a Perkin Elmer Sciex API 300 LC-MS/MS system (Perkin Elmer Überlingen). 
Samples were dissolved in water/methanol $(1: 1, \mathrm{v} / \mathrm{v})$ and injected into the mass spectrometer via a syringe pump (Harvard Apparatus) at a flow of $5 \mu \mathrm{min}^{-1}$. Ionization was achieved in the negative mode with the ion spray interface set at $-3.5 \mathrm{kV}$. Nitrogen was used as nebulizer gas $\left(1.51 \mathrm{~min}^{-1}\right)$ and curtain gas $\left(1.21 \mathrm{~min}^{-1}\right)$. Lens and quadrupole parameters were set as follows: orifice $-30 \mathrm{~V}$, focusing ring $-200 \mathrm{~V}$, Q0 $10 \mathrm{~V}$. All other parameters were optimized with regard to signal intensity. LC2 Tune 1.2 and Multiview 1.2 software (Perkin Elmer Sciex) were used for data acquisition and evaluation.

\section{RESULTS}

\section{Characterization of the fluoranthene-degrading isolate strain KR20}

Strain KR20 (Rehmann et al., 1999) was isolated from a PAH-contaminated soil by its ability to utilize fluoranthene as sole source of carbon and energy. The rod-shaped (diameter $0.5-0.8 \mu \mathrm{m}$, length $1.5-2 \mu \mathrm{m}$ ), Gram-negative, non-motile bacterium produced smooth, yellow, scotochromogenic colonies of $2-3 \mathrm{~mm}$ diameter on R2A agar plates after $7 \mathrm{~d}$ at $25^{\circ} \mathrm{C}$. Due to its pronounced acid-fastness, its mycolic acid pattern, which was similar to that of Mycobacterium phleii DSM 43239, and its ability to utilize Tween 80, another taxonomic characteristic (Wayne et al., 1974), isolate KR20 was assigned to the genus Mycobacterium. For growth on fluoranthene $(10 \mathrm{ml}$ batch cultures, $0.5 \mathrm{mg}$ fluoranthene $\mathrm{ml}^{-1}$ ) a linear relationship between the turbidity $\left(\mathrm{OD}_{578}\right)$ of the cultures and the number of c.f.u. was observed in the range of $\mathrm{OD}_{578} 0 \cdot 03-0.5$

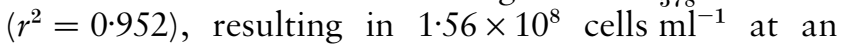
$\mathrm{OD}_{578}$ of $0 \cdot 1$.

Although metabolites were produced from several other PAHs (Table 1) none of these compounds was able to support the growth of strain KR20, i.e. they failed to increase the number of c.f.u. over a $14 \mathrm{~d}$ incubation period.

\section{Fluoranthene metabolites}

Structures of known bacterial fluoranthene degradation intermediates and the corresponding degradation pathways are summarized in Fig. 1. Seven metabolites were produced by strain KR20 from fluoranthene in detectable amounts. They could be differentiated into three neutral and four acidic compounds by sequential neutral and acidic ethyl acetate extraction of the cultures (Rehmann et al., 1999). Comparison of the UV-Vis spectra of the metabolites with those of known PAH metabolites gave a first indication of the identity of the compounds.

Metabolite I had no UV-Vis absorption maximum above $220 \mathrm{~nm}$ (Fig. 2). Its ${ }^{1} \mathrm{H}-\mathrm{NMR}$ spectrum (Table 2), showing only two signals in the aromatic region with a $2 / 1$ intensity ratio, indicated a 1,2,3-symmetrically substituted benzene skeleton. The corresponding ${ }^{13} \mathrm{C}$ NMR data (Table 2) revealed six signals, two of which showed a chemical shift characteristic of carboxy carbon atoms. In accordance with the symmetry requirements imposed by the ${ }^{1} \mathrm{H}-\mathrm{NMR}$ signature, the investigation of ${ }^{3} J(\mathrm{CH})$ coupling (Table 2 ) indicated that the six signals observed in the ${ }^{13} \mathrm{C}-\mathrm{NMR}$ spectrum were caused by nine carbon atoms, the actual number of carboxy substituents being three. The correct assignment of the resulting structure benzene-1,2,3-tricarboxylic acid (hemimellitic acid) was checked by MS techniques. Metabolite I could not be derivatized with MSTFA for GC-MS analysis; however, direct-infusion HPLCnegative-mode MS derived mass spectra showed the expected $\mathrm{M}-\mathrm{H}$ signal at $m / z$ 209. Fragment ions were observed at $m / z \quad 191\left(\mathrm{M}-\mathrm{H}-\mathrm{H}_{2} \mathrm{O}\right), 165$ $\left(\mathrm{M}-\mathrm{H}-\mathrm{CO}_{2}\right), 147\left(\mathrm{M}-\mathrm{H}-\mathrm{CO}_{2}-\mathrm{H}_{2} \mathrm{O}\right)$ and $121(\mathrm{BP}$;

Table 1. Metabolism of substrates other than fluoranthene by Mycobacterium sp. strain KR20 cells after $14 \mathrm{~d}$ incubation

\begin{tabular}{|lcc|}
\hline Substrate $\left(\mathbf{0} \cdot \mathbf{5} \mathbf{~ m g ~ m l}^{-1}\right)$ & \multicolumn{2}{c|}{ Metabolites } \\
\cline { 2 - 3 } & $n^{*}$ & Structure proposal $\dagger$ \\
\hline None & - & - \\
Biphenyl & - & - \\
Naphthalene & 1 & \\
Anthracene & 2 & 1,2-Anthracene dihydrodiol \\
Fluorene & 1 & 9-Hydroxyfluorene \\
Phenanthrene & 3 & Diphenic acid, 3-hydroxyphenanthrene \\
Pyrene & 4 & 4,5-Pyrene dihydrodiol, 4,5-phenanthrene dicarboxylic \\
Chrysene & & acid, pyrene metabolite VI \\
\hline
\end{tabular}

$* n$, number of metabolites detected

† Preliminary structure assignments are based on UV-Vis spectral data as obtained by diode-array detection during HPLC analysis of ethyl acetate extracts of the acidified cultures (HPLC conditions same as for fluoranthene metabolite separation).

‡ See Rehmann et al. (1999). 

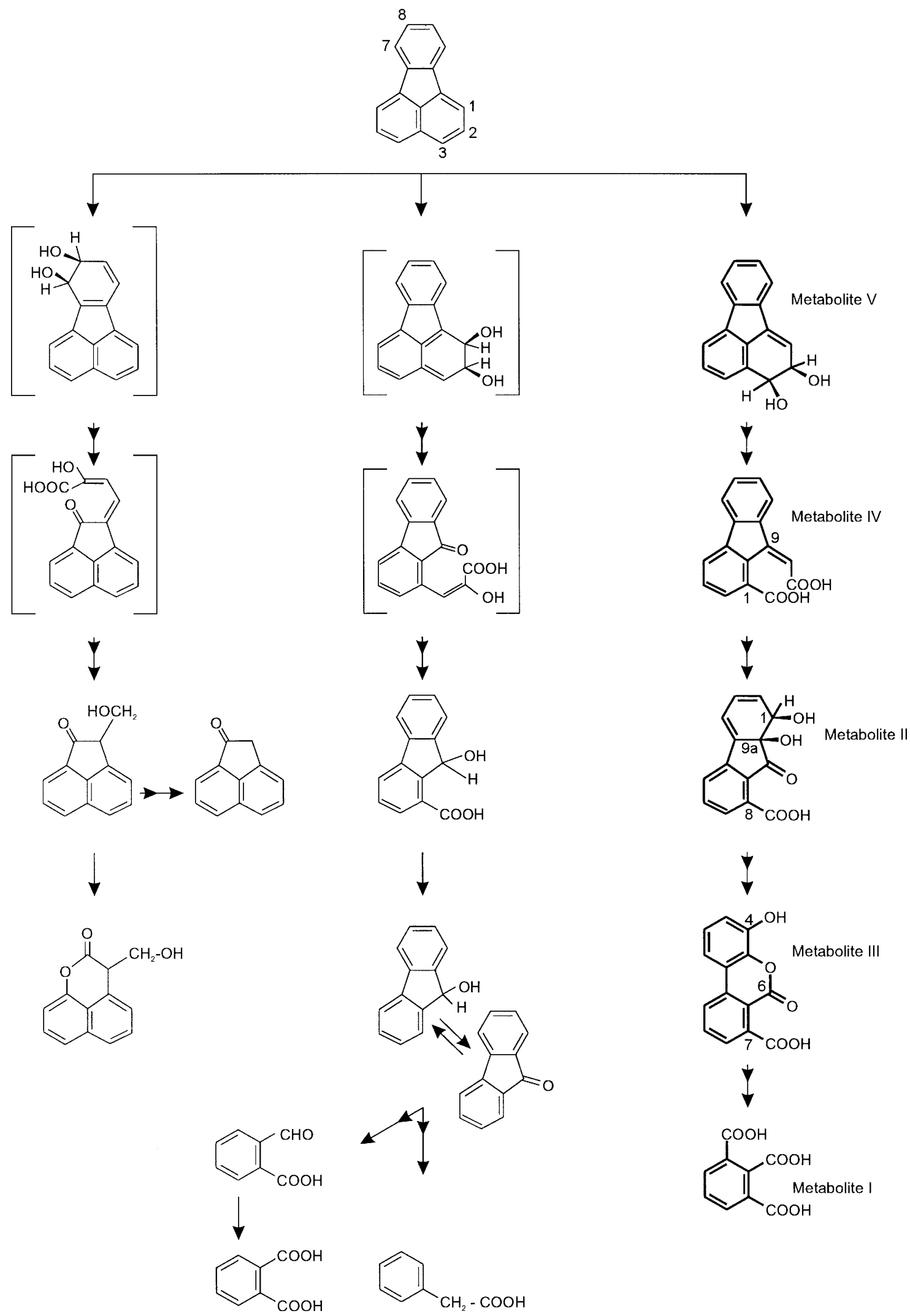

Fig. 1. Synopsis of bacterial fluoranthene degradation pathways described to date: left column, Weißenfels et al. (1990); middle column, Kelley et al. (1993); right column, Rehmann et al. (1999). Single arrows indicate one-step reactions, double arrows transformations of two or more steps. Hypothetical intermediates are shown in square brackets. Ring numbering follows IUPAC rules; cf. Tables 2-6. 

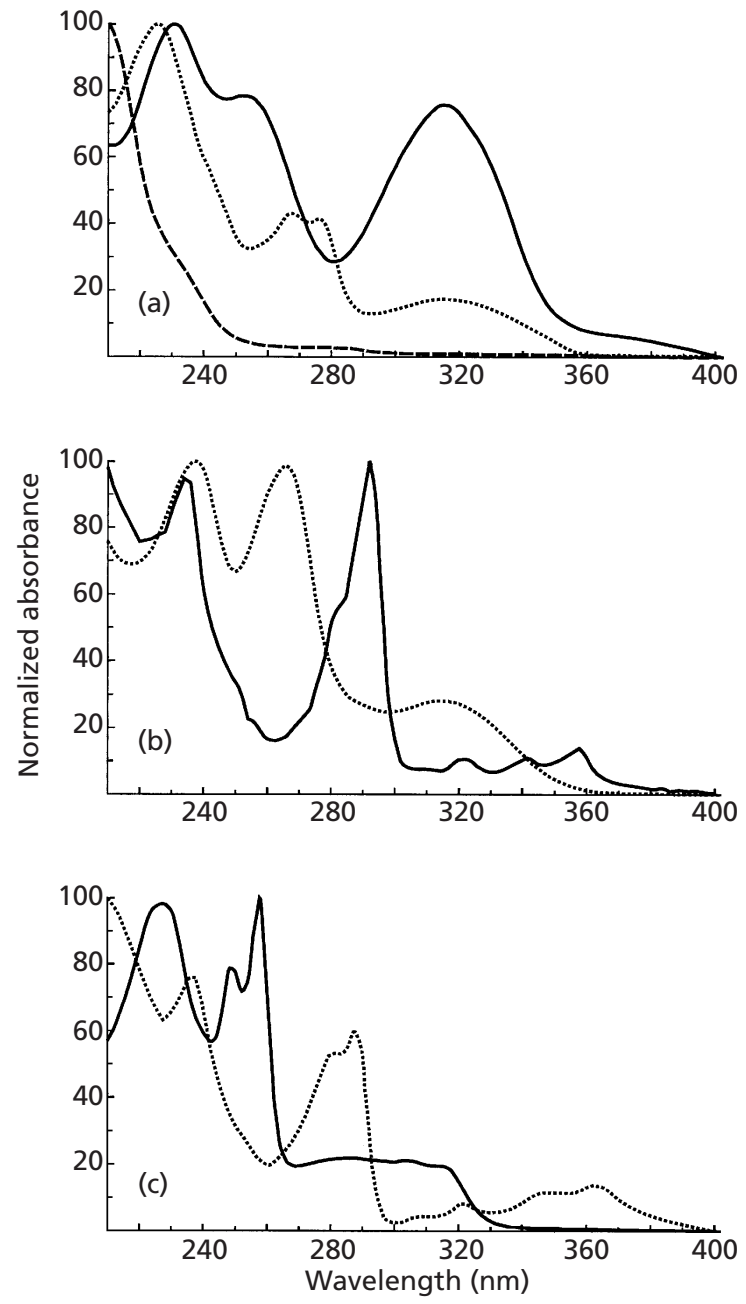

Fig. 2. UV-Vis spectra of fluoranthene metabolites I-VII of Mycobacterium sp. strain KR2O as obtained during HPLC analysis of ethyl acetate culture extracts by diode-array detection, corrected for solvent background. (a) ---, Metabolite $\mathrm{I} ; \ldots$, metabolite II; $\cdots$, metabolite III. (b) $\cdots$, Metabolite IV; —, metabolite $\mathrm{VI}$, (c) $\cdots$, Metabolite $\mathrm{VII} ; \_$, metabolite V.

$\left.\mathrm{M}-\mathrm{H}-2 \mathrm{CO}_{2}\right)$. The structure was finally confirmed by co-chromatographic HPLC analysis and direct-infusion HPLC-MS comparison of authentic hemimellitic acid.

The UV-Vis spectrum of metabolite II (Fig. 2) was very similar to the UV-Vis spectrum of cis-1,9a-dihydroxy-1hydrofluoren-9-one (Grifoll et al., 1994). The ${ }^{1} \mathrm{H}-\mathrm{NMR}$ data (Table 3) also revealed a striking similarity to the ${ }^{1} \mathrm{H}-\mathrm{NMR}$ spectrum of this compound (Selifonov et al., 1993), the only difference being a substituted carbon atom in ring position 8 . The ${ }^{13} \mathrm{C}-\mathrm{NMR}$ spectrum (Table 3 ) showed an insufficient signal/noise ratio due to the limited amount of material available. Additional weak quaternary carbon atom signals were observed at $133 \cdot 3$, $134 \cdot 7,144 \cdot 4$ and $147 \cdot 8$ p.p.m., with two further signals missing which were expected from the structure. The signals could not unequivocally be assigned to the non- hydrogen-bearing carbon atoms at ring positions $4 \mathrm{a}, 4 \mathrm{~b}$, 8, 8a, 9, and 9a. However, the substituent at ring position 8 could be identified from the ${ }^{13} \mathrm{C}-\mathrm{NMR}$ spectrum as carboxylic acid methyl ester. From the increased HPLC retention time observed for the purified compound ( $15.2 \mathrm{~min})$ as compared to metabolite II in culture extracts $(13.2 \mathrm{~min})$, it was concluded that metabolite II artificially recruited the methoxy group during purification due to the concentration process of the acidified methanolic clean-up fractions. Thus native metabolite II was assigned the structure cis-1,9adihydroxy-1-hydrofluoren-9-one-8-carboxylic acid. GCMS analysis of the trimethylsilylated derivative of metabolite II methyl ester confirmed this assignment. As expected the molecule ion signal was observed at $\mathrm{m} / z \quad 416$ (BP, 100\%). Characteristic fragment ions were detected at $m / z$ $401\left(18.6 \%, \mathrm{M}^{+}-\mathrm{CH}_{3}\right), 385$ $\left(8.8 \%, \quad \mathrm{M}^{+}-\mathrm{OCH}_{3}, \quad\right.$ ester group), $369(16.2 \%$, $\left.\mathrm{M}^{+}-\mathrm{CH}_{3} \mathrm{OH}-\mathrm{CH}_{3}\right), 327\left(14 \cdot 9 \%, \mathrm{M}^{+}-\mathrm{OTMS}\right), 311$ $\left(73.5 \%, \mathrm{M}^{+}\right.$- HOTMS - $\left.\mathrm{CH}_{3}\right), 297\left(10 \cdot 3 \%, \mathrm{M}^{+}-\right.$ OTMS $\left.-2 \mathrm{CH}_{3}\right), 269(11 \cdot 2 \%)$ and $223\left(84 \cdot 2 \%, \mathrm{M}^{+}-\right.$ 2OTMS $-\mathrm{CH}_{3}$ ).

Comparison of the UV-Vis spectra of metabolite III (Fig. 2) and of 4-hydroxy-benzo[c] chromene-6-one [designated by Grifoll et al. (1994) as 8-hydroxy-3,4-benzocoumarin] indicated a high degree of concurrence. The same held for the NMR characteristics of both compounds. Metabolite III differed in only one position: the ring carbon atom on position 7 of the 4-hydroxybenzo[c]chromene-6-one skeleton. By ${ }^{13} \mathrm{C}-\mathrm{NMR}$ measurements (Table 4) this carbon atom was shown to carry a carboxy group. The unequivocal signal assignment in ${ }^{1} \mathrm{H}-\mathrm{NMR}$ and ${ }^{13} \mathrm{C}-\mathrm{NMR}$ spectra was carried out by a combination of HMQC and HMBC spectra. The deduced structure of metabolite III, 4-hydroxy-benzo[c]chromene-6-one-7-carboxylic acid, was further confirmed by GC-MS analysis of the MSTFA-derivatized compound. Its mass spectrum, which showed the expected $\mathrm{M}^{+}$signal at $\mathrm{m} / z 400$ $(22.7 \%)$, gave only a poor fragmentation pattern with fragment ions observed at $\mathrm{m} / z \quad 385$ (BP, $100 \%$, $\left.\mathrm{M}^{+}-\mathrm{CH}_{3}\right), 311\left(7 \cdot 8 \%, \mathrm{M}^{+}-\mathrm{OTMS}\right), 240\left(3 \cdot 9 \%, \mathrm{M}^{+}-\right.$ TMS $\left.-\mathrm{COOH}-\mathrm{CO}-\mathrm{CH}_{3}\right)$ and $210\left(4 \cdot 2 \%, \mathrm{M}^{+}-\right.$ 2HOTMS).

The ${ }^{1} \mathrm{H}-\mathrm{NMR}$ data of metabolite IV (Table 5) revealed the presence of three mutually coupling groups encompassing one methylene proton, and four and three aromatic protons, respectively. The succession of the protons as deduced from ${ }^{1} \mathrm{H},{ }^{1} \mathrm{H}-\mathrm{COSY}$ and ${ }^{1} \mathrm{H},{ }^{1} \mathrm{H}$ NOESY experiments suggested that the basic molecular frame was a fluorene substituted at ring positions 1 and 9 , the latter resulting from a ring opening between the carbon atoms 2 and 3 of the parent compound fluoranthene. The ${ }^{13} \mathrm{C}$-NMR signature of metabolite IV (Table 5) encompassed 14 signals, only seven of which showed directly bound protons as demonstrated by a DEPT 135 (distortionless enhancement by polarization transfer) experiment. A ${ }^{1} \mathrm{H},{ }^{13} \mathrm{C}-\mathrm{HMQC}$ spectrum revealed that the signal observed at 130.95 p.p.m. was actually caused by two carbon atoms occupying ring 
Table 2. NMR data of fluoranthene metabolite I, benzene-1,2,3-tricarboxylic acid, hemimellitic acid (methanol- $d_{4}, 30^{\circ} \mathrm{C}$ )

r, ring atom position.

$\begin{array}{lcccccc}{ }^{13} \text { C-NMR } & & & & & \\ \text { Structural assignments } & \mathrm{r} 1 / \mathrm{r} 3 & \mathrm{r} 2 & \mathrm{r} 4 / \mathrm{r} 6 & \mathrm{r} 5 & \text { at } \mathrm{r} 1 / \mathrm{r} 3 & \text { at } \mathrm{r} 2 \\ \text { Chemical shift (p.p.m.) } & 130 \cdot 85 & 138 \cdot 63 & 134 \cdot 94 & 130 \cdot 09 & 168 \cdot 46 & 172 \cdot 82 \\ & & & + & + & \text { carboxylate } \\ { }^{1} J(\mathrm{CH}) & \mathrm{r} 5 & \mathrm{r} 4 & & & \mathrm{r} 4 \\ { }^{3} J(\mathrm{CH}) \text { to proton at } & & & & & \\ { }^{1} \mathrm{H}-\mathrm{NMR} & & \text { at } \mathrm{r} 4 / \mathrm{r} 6 & \text { at } \mathrm{r} 5 & \\ \text { Structural assignments } & & 8 \cdot 17 & 7 \cdot 61 & \\ \text { Chemical shift (p.p.m.) } & & 2 & 1 & \\ \text { Signal intensity } & & \mathrm{d} & \mathrm{t} & \\ \text { Signal multiplicity } & & 7 \cdot 8 & 7 \cdot 9 & \\ { }^{3} J \text { coupling constants }(\mathrm{Hz}) & & & & \end{array}$

* The signals of the carboxylate protons were invisible due to chemical exchange.

Table 3. NMR data of fluoranthene metabolite II, cis-1,9a-dihydroxy-1-hydrofluoren-9-one-8-carboxylic acid methyl ester (chloroform- $d_{1}, 30^{\circ} \mathrm{C}$ )

$\mathrm{r}$, ring atom position.

\begin{tabular}{|c|c|c|c|c|c|c|c|c|c|}
\hline \multicolumn{10}{|l|}{${ }^{13} \mathrm{C}-\mathrm{NMR} *$} \\
\hline Structural assignments & $\mathrm{r} 1$ & $\mathrm{r} 2$ & r3 & $\mathrm{r} 4$ & $\mathrm{r} 5 \dagger$ & r6 & $\mathrm{r} 7 \dagger$ & at $\mathrm{r} 8$ & $\mathrm{OCH}_{3}$ \\
\hline Chemical shift (p.p.m.) & $70 \cdot 73$ & $133 \cdot 58$ & $123 \cdot 72$ & $118 \cdot 92$ & $135 \cdot 37$ & $129 \cdot 82$ & $124 \cdot 64$ & $166 \cdot 69$ & $52 \cdot 78$ \\
\hline${ }^{1} J(\mathrm{CH})$ & + & + & + & + & + & + & + & carboxy & + \\
\hline \multicolumn{10}{|l|}{${ }^{1} \mathrm{H}-\mathrm{NMR}$} \\
\hline Structural assignments & at $\mathrm{r} 1$ & at $\mathrm{r} 2$ & at $\mathrm{r} 3$ & at $\mathrm{r} 4$ & at $\mathrm{r} 5$ & at $\mathrm{r} 6$ & at $\mathrm{r} 7$ & & at $\mathrm{OCH}_{3}$ \\
\hline Chemical shift (p.p.m.) $\neq$ & $4 \cdot 73$ & $5 \cdot 96$ & $6 \cdot 22$ & $6 \cdot 63$ & $7 \cdot 68$ & $7 \cdot 70$ & $7 \cdot 84$ & & 3.97 \\
\hline Signal intensity & 1 & 1 & 1 & 1 & 1 & 1 & 1 & & 3 \\
\hline Signal multiplicity & $\mathrm{d}$ & $\mathrm{dd}$ & ddd & $\mathrm{d}$ & dd & $\mathrm{dd}$ & $\mathrm{dd}$ & & s \\
\hline \multirow[t]{2}{*}{${ }^{3} J$ coupling constants $(\mathrm{Hz})$} & $2 \cdot 0$ & $2 \cdot 0$ & $9 \cdot 6$ & $5 \cdot 1$ & $7 \cdot 4$ & $7 \cdot 5$ & $7 \cdot 5$ & & \\
\hline & & $9 \cdot 6$ & $5 \cdot 1$ & & & $7 \cdot 5$ & & & \\
\hline
\end{tabular}

*Additional weak quaternary carbon atom signals were observed at $133 \cdot 3,134 \cdot 7144 \cdot 4$ and $147 \cdot 8$ p.p.m. These signals could not unequivocally be assigned.

† Deduced by comparison with the ${ }^{1} \mathrm{H}-\mathrm{NMR}$ data published for cis-1,9a-dihydroxy-1-hydrofluoren-9-one (Selifonov et al., 1993).

$\ddagger$ The signals of exchangeable protons were invisible due to traces of water in the sample.

positions 3 and 6 in the supposed fluorene scaffold. The remaining seven ${ }^{13} \mathrm{C}$ signals could be subdivided into six $\mathrm{sp}^{2}$-hybridized carbon atoms and one carboxylic carbon atom. A ${ }^{1} \mathrm{H},{ }^{13} \mathrm{C}-\mathrm{HMBC}$ experiment, performed to establish the assignment of the non-hydrogen substituted carbon resonances, revealed the presence of a second carboxy group (Table 5) bound to the carbon at ring position 1. Metabolite IV was assigned the structure of Z-9-carboxymethylenefluorene-1-carboxylic acid. The Z-configuration of the carboxy and fluorene 'substituents' of the methylene group was deduced from the ${ }^{1} \mathrm{H},{ }^{1} \mathrm{H}-\mathrm{NOE}$ (nuclear Overhauser effect) observed with the methylene proton and the proton at ring carbon atom on position 8 . The mass spectrum obtained from the trimethylsilylated derivative of metabolite IV was in accordance with the structure proposed, providing an $\mathrm{M}^{+}$signal at $m / z 410(10 \cdot 3 \%)$. Fragmentation was even poorer than that observed with metabolite III. Signals were detected at $m / z 395\left(8.8 \%, \mathrm{M}^{+}-\mathrm{CH}_{3}\right), 293$ (BP, $\left.100 \%, \mathrm{M}^{+}-\mathrm{TMS}-\mathrm{CO}_{2},\right), 235\left(2 \cdot 3 \%, \mathrm{M}^{+}-2 \mathrm{TMS}-\right.$ $\mathrm{CHO}), 190\left(2 \cdot 1 \% \mathrm{M}^{+}-2 \mathrm{TMS}-\mathrm{CO}_{2}-\mathrm{CH}_{2} \mathrm{O}\right)$ and $176\left(3 \cdot 1 \%, \mathrm{M}^{+}-2 \mathrm{TMS}-2 \mathrm{CO}_{2}\right)$.

Metabolite V had a UV-Vis spectrum (Fig. 2) almost identical to that of trans-2,3-fluoranthene dihydrodiol as published by Babson et al. (1986) and Pothuluri et al. (1992). The assignment of the fluoranthene dihydrodiol structure was confirmed by the results of the GC-MS analysis of the MSTFA-derivatized compound. The mass spectrum showed the expected $\mathrm{M}^{+}$signal at $\mathrm{m} / z$ 380 (BP, $100 \%$ ). Prominent fragment ions were detected at $m / z 365\left(3.9 \%, \mathrm{M}^{+}-\mathrm{CH}_{3}\right), 349\left(6 \cdot 3 \%, \mathrm{M}^{+}\right.$ $\left.-\mathrm{CH}_{3} \mathrm{O}\right), 291\left(27 \cdot 3 \%, \mathrm{M}^{+}-\mathrm{OTMS}\right), 290(25 \cdot 7 \%$, $\mathrm{M}^{+}$-HOTMS), $275\left(12 \cdot 3 \%, \mathrm{M}^{+}-\mathrm{HOTMS}-\mathrm{CH}_{3}\right)$, 
Table 4. NMR data of fluoranthene metabolite III, 4-hydroxy-benzo[c]chromene-6-one-7-carboxylic acid (acetone- $d_{6,}$ $\left.30^{\circ} \mathrm{C}\right)$

$\mathrm{r}$, ring atom position.

\begin{tabular}{|c|c|c|c|c|c|c|c|c|c|c|c|c|c|c|c|}
\hline \multicolumn{16}{|l|}{${ }^{13} \mathrm{C}-\mathrm{NMR}$} \\
\hline Structural assignments & $\mathrm{r} 1$ & $\mathrm{r} 2$ & $\mathrm{r} 3$ & r4 & $\mathrm{r} 4 \mathrm{a}$ & $\mathrm{r} 5$ & r6 & r6a & $\mathrm{r} 7$ & r8 & r9 & $\mathrm{r} 10$ & $\mathrm{r} 10 \mathrm{a}$ & $\mathrm{r} 10 \mathrm{~b}$ & at $\mathrm{r} 7$ \\
\hline Chemical shift (p.p.m.) & $114 \cdot 81$ & $125 \cdot 60$ & $118 \cdot 36$ & $146 \cdot 23$ & $140 \cdot 95$ & $\begin{array}{c}\text { oxygen } \\
\text { atom }\end{array}$ & $158 \cdot 93$ & $136 \cdot 78$ & $139 \cdot 27$ & $128 \cdot 32$ & $135 \cdot 36$ & $124 \cdot 41$ & $118 \cdot 15$ & $119 \cdot 25$ & $169 \cdot 98$ \\
\hline $\begin{array}{l}{ }^{1} J(\mathrm{CH}) \\
{ }^{n} J(\mathrm{CH}) \text { to proton at }\end{array}$ & + & + & + & $r 3 *$ & $r 2^{* \ldots \ldots}$ & & $\begin{array}{l}\text { lactone } \\
\mathrm{r} 10^{* * * * *}\end{array}$ & $r 9^{* * * * *}$ & $\mathrm{r} 9^{2 * * *}$ & + & + & + & $\mathrm{r} 10^{* *}$ & $r 2^{2 * * *}$ & $\begin{array}{c}\text { carboxy } \\
\mathrm{r} 8^{* * * *}\end{array}$ \\
\hline \multicolumn{16}{|l|}{${ }^{1} \mathrm{H}-\mathrm{NMR}$} \\
\hline Structural assignments & at $\mathrm{r} 1$ & at $\mathrm{r} 2$ & at $\mathrm{r} 3$ & at $\mathrm{r} 4$ & & & & & & at $\mathrm{r} 8$ & at $\mathrm{r} 9$ & at $\mathrm{r} 10$ & & & \\
\hline Chemical shift (p.p.m.) & $7 \cdot 78$ & $7 \cdot 25$ & $7 \cdot 14$ & $8.90 \dagger$ & & & & & & 7.63 & 7.98 & $8 \cdot 43$ & & & $11 \cdot 45 \$$ \\
\hline Signal intensity & 1 & 1 & 1 & $-\ddagger$ & & & & & & 1 & 1 & 1 & & & $-\ddagger$ \\
\hline Signal multiplicity & dd & dd & $\mathrm{dd}$ & s & & & & & & $\mathrm{dd}$ & dd & dd & & & \\
\hline \multirow[t]{2}{*}{${ }^{3} J(\mathrm{~Hz})$} & $8 \cdot 2$ & $8 \cdot 1$ & & & & & & & & $7 \cdot 4$ & $7 \cdot 5$ & & & & \\
\hline & & 8.0 & $8 \cdot 0$ & & & & & & & & $8 \cdot 1$ & $8 \cdot 3$ & & & \\
\hline
\end{tabular}

*The data presented are from ${ }^{1} \mathrm{H},{ }^{13} \mathrm{C}-\mathrm{HMBC}$ experiments and show the strongest interactions observed $(* * n=2 ; * * * n=3$; $* * * * n=4)$.

† Hydroxyl proton.

$\ddagger$ Not integrated due to signal broadening.

SCarboxylate proton.

Table 5. NMR data of fluoranthene metabolite IV, Z-9-carboxymethylene-fluorene-1-carboxylic acid (methanol- $d_{4}$ $\left.30^{\circ} \mathrm{C}\right)$

$\mathrm{r}$, ring atom position.

\begin{tabular}{|c|c|c|c|c|c|c|c|c|c|c|c|c|c|c|c|c|}
\hline \multicolumn{17}{|l|}{${ }^{13} \mathrm{C}-\mathrm{NMR}$} \\
\hline Structural assignments & r1 & $\mathrm{r} 2$ & $\mathrm{r} 3$ & $\mathrm{r} 4$ & r4a & $\mathrm{r} 4 \mathrm{~b}$ & $\mathrm{r} 5$ & r6 & $\mathrm{r} 7$ & r8 & r8a & $\mathrm{r} 9$ & $\mathrm{r} 9 \mathrm{a}$ & at $\mathrm{r} 1$ & 10 at $\mathrm{r} 9$ & at 10 \\
\hline Chemical shift (p.p.m.)* & $134 \cdot 39$ & $129 \cdot 65$ & $130 \cdot 95$ & $123 \cdot 40$ & $144 \cdot 84$ & 139.89 & $120 \cdot 88$ & $130 \cdot 95$ & $129 \cdot 06$ & $121 \cdot 80$ & $141 \cdot 12$ & $145 \cdot 65$ & $135 \cdot 42$ & $171 \cdot 76$ & $120 \cdot 15$ & $170 \cdot 47$ \\
\hline${ }^{1} J(\mathrm{CH})$ & & + & + & + & & & + & + & + & + & & & & carboxy & + & carboxy \\
\hline${ }^{n} J(\mathrm{CH})$ to proton at $\dagger$ & r3 & & & & $\mathrm{r} 3 / \mathrm{r} 5$ & $\mathrm{r} 4 / \mathrm{r} 6$ & & & & & $10 / \mathrm{r} 7$ & r8 & $\mathrm{r} 4 / \mathrm{r} 2$ & $\mathrm{r} 2$ & & $10+t$ \\
\hline \multicolumn{17}{|l|}{${ }^{1} \mathrm{H}-\mathrm{NMR}$} \\
\hline Structural assignments & & at $\mathrm{r} 2$ & at $\mathrm{r} 3$ & at $\mathrm{r} 4$ & & & at $\mathrm{r} 5$ & at $\mathrm{r} 6$ & at $r 7$ & at $\mathrm{r} 8$ & & & & & at 10 & \\
\hline Chemical shift (p.p.m.) & & 7.71 & $7 \cdot 51$ & $7 \cdot 91$ & & & $7 \cdot 76$ & $7 \cdot 43$ & $7 \cdot 34$ & $7 \cdot 80$ & & & & & 6.89 & \\
\hline Signal intensity & & 1 & 1 & 1 & & & 1 & 1 & 1 & 1 & & & & & 1 & \\
\hline Signal multiplicity & & $\mathrm{dd}$ & dd & dd & & & d & ddd & ddd & d & & & & & s & \\
\hline \multirow[t]{2}{*}{${ }^{3} J$ coupling constants $(\mathrm{Hz})$} & & $7 \cdot 7$ & $7 \cdot 7$ & & & & $7 \cdot 5$ & $7 \cdot 5$ & $7 \cdot 4$ & & & & & & & \\
\hline & & & $7 \cdot 6$ & $7 \cdot 3$ & & & & $7 \cdot 4$ & $7 \cdot 7$ & $7 \cdot 7$ & & & & & & \\
\hline
\end{tabular}

* Complete overlap of the signals of the carbon atoms assigned to positions 3 and 6 was recognized from a ${ }^{1} \mathrm{H},{ }^{13} \mathrm{C}-\mathrm{HMQC}$ experiment. The signal of the carboxy group connected to ring position 1 was detected with a ${ }^{1} \mathrm{H},{ }^{13} \mathrm{C}-\mathrm{HMBC}$-experiment.

† The data presented are from ${ }^{1} \mathrm{H},{ }^{13} \mathrm{C}-\mathrm{HMBC}$ experiments and show the strongest interactions observed $(n=3,+\dagger n=2)$.

$\ddagger$ The signals of the carboxylate protons were invisible due to chemical exchange.

Table 6. ${ }^{1} \mathrm{H}-\mathrm{NMR}$ data of fluoranthene metabolite $\mathrm{V}$, cis-2,3-fluoranthene dihydrodiol (acetone- $d_{6}, 30^{\circ} \mathrm{C}$ )

$\mathrm{r}$, ring atom position

\begin{tabular}{|c|c|c|c|c|c|c|c|c|c|c|}
\hline Structural assignments & $\mathrm{r} 1$ & r2 & r3 & r4 & $\mathrm{r} 5$ & r6 & $\mathrm{r} 7$ & r8 & r9 & r10 \\
\hline Chemical shift (p.p.m.) & $6 \cdot 73$ & $\begin{array}{l}4.72 / \\
4 \cdot 15^{*}\end{array}$ & $\begin{array}{l}4 \cdot 88 / \\
4 \cdot 10^{*}\end{array}$ & $7 \cdot 39$ & $7 \cdot 37$ & $7 \cdot 64$ & $7 \cdot 80$ & $7 \cdot 40$ & $7 \cdot 33$ & $7 \cdot 82$ \\
\hline Signal intensity & 1 & $1 /-\dagger$ & $1 /-\dagger$ & 1 & 1 & 1 & 1 & 1 & 1 & 1 \\
\hline Signal multiplicity & d & dd & d & $\mathrm{d}$ & $\mathrm{dd}$ & $\mathrm{d}$ & $\mathrm{d}$ & ddd & ddd & $\mathrm{d}$ \\
\hline${ }^{3} J$ coupling constants $(\mathrm{Hz}) \mathbb{S}$ & $4 \cdot 1$ & $\begin{array}{c}4 \cdot 1 \\
5 \cdot 4\end{array}$ & $5 \cdot 4$ & $7 \cdot 2$ & $\begin{array}{c}7 \cdot 3 \\
7 \cdot 4\end{array}$ & $7 \cdot 2$ & $7 \cdot 5$ & $\begin{array}{c}7 \cdot 5 \\
7 \cdot 5\end{array}$ & $\begin{array}{c}7 \cdot 5 \\
7 \cdot 4\end{array}$ & $7 \cdot 5$ \\
\hline
\end{tabular}

*Hydroxyl protons.

† Hydroxyl protons not integrated due to signal broadening. $\neq$ After addition of $\mathrm{H}_{2} \mathrm{O}$ to exchange the hydroxyl protons.

$\mathbb{S}$ The coupling constants of the cis-protons are given in bold. 
$218\left(32 \cdot 5 \%, \mathrm{M}^{+}-\mathrm{TMS}-\mathrm{OTMS}\right)$ and $202(17 \cdot 5 \%$, $\left.\mathrm{M}^{+}-2 \mathrm{OTMS}\right)$. The ${ }^{1} \mathrm{H}-\mathrm{NMR}$ data of metabolite $\mathrm{V}$ (Table 6) again were in good accordance with those of trans-2,3-fluoranthene dihydrodiol (Pothuluri et al., 1992; Rice et al., 1983). However, the ${ }^{3} J$ vicinal coupling constant between the protons at ring positions 2 and 3 was different : $5 \cdot 4 \mathrm{~Hz}$ as compared to $8 \mathrm{~Hz}$ for trans-2,3fluoranthene dihydrodiol, suggesting a cis-orientation of the substituents. Such smaller coupling constants of the cis-isomers were also reported for the 1,2-dihydrodiols of naphthalene, anthracene and phenanthrene (Jeffrey et al., 1975; Jerina et al., 1976).

The UV-Vis spectra of metabolites VI and VII (Fig. 2) showed a striking similarity to the UV-Vis spectra of 8-hydroxyfluoranthene and 3-hydroxyfluoranthene (Babson et al., 1986) and were thus assigned these structures. They could not be characterized in more detail because their concentrations varied very markedly from experiment to experiment.

\section{Time course of fluoranthene degradation}

Fluoranthene metabolism of Mycobacterium sp. strain KR20 was monitored over $624 \mathrm{~h}$ (Fig. 3) using $10 \mathrm{ml}$ batch cultures which were inoculated to an $\mathrm{OD}_{578}$ of 0.03 with cells pre-grown on fluoranthene for $6 \mathrm{~d}$. Fluoranthene degradation started without an apparent lag and cell counts began to rise after $48 \mathrm{~h}$. Maximum c.f.u. numbers (about $6.2 \times 10^{8}$ cells $\mathrm{ml}^{-1}$ ), a 30 -fold increase compared to the inoculum, were obtained between day 10 and 14 of the cultivation period, when $\geqslant 60 \%$ of the initial fluoranthene content was metabolized. The c.f.u. numbers decreased considerably afterwards. The fluoranthene degradation eventually reached $>96 \%$, whereas sterile controls run in parallel showed no loss of fluoranthene after $624 \mathrm{~h}$.

Metabolites I to IV could be quantified from the beginning of the experiment. In contrast, metabolite $\mathrm{V}$, cis-2,3-fluoranthene dihydrodiol, was detected only in trace amounts over the whole incubation period. Absolute concentrations could only be determined for metabolite I, as sufficient amounts for HPLC calibration of metabolites II to IV could not be obtained. Metabolite I reached a maximum concentration of $8 \mu \mathrm{g} \mathrm{ml}^{-1}$, which accounted for about $0.8 \%$ of the fluoranthene carbon added. The concentrations of all metabolites increased up to day 10-14. Later on, the concentration of metabolite I increased further, whereas the concentrations of metabolites II and IV reached a plateau and the concentration of metabolite III decreased after $20 \mathrm{~d}$.

The situation when non-fluoranthene-grown inocula were used was slightly different (data not shown). As indicated by the turbidity increase of these cultures, cells started to grow only after a lag phase of about $72 \mathrm{~h}$. Depending on the respective experiment a temporary accumulation of cis-2,3-fluoranthene dihydrodiol during the first $120 \mathrm{~h}$ up to $192 \mathrm{~h}$ of incubation could be observed.
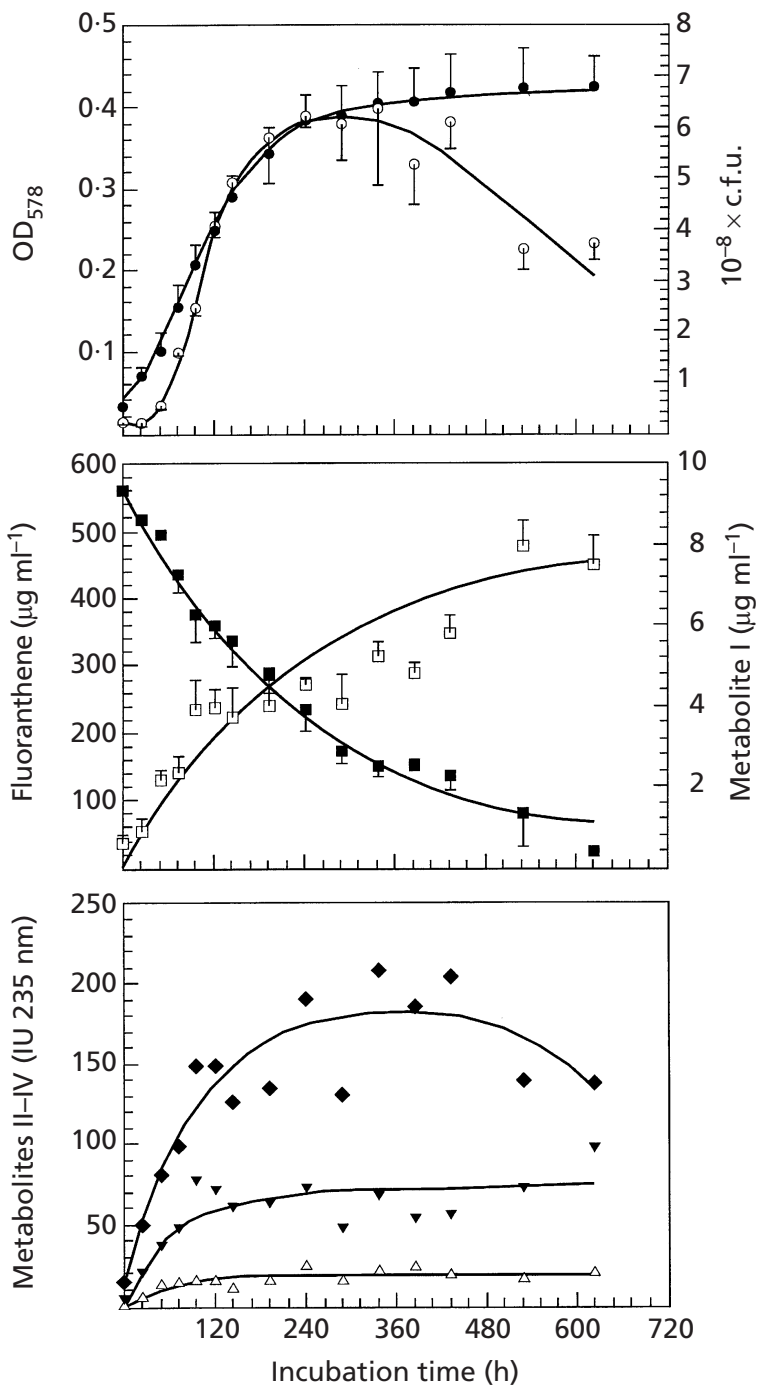

Fig. 3. Fluoranthene degradation and metabolite formation by Mycobacterium sp. strain KR20. The optical density values represent the mean of six $10 \mathrm{ml}$ cultures; the c.f.u. numbers and concentration determinations represent the mean of three $10 \mathrm{ml}$ cultures. Error bars indicate the standard deviation (plotted unidirectionally for better visibility). The inoculum was pre-grown on fluoranthene. $\bigcirc$, c.f.u.; 0 , optical density; $\mathbf{\square}$, fluoranthene; $\square$, metabolite I; $\boldsymbol{\nabla}$, metabolite II; $\diamond$, metabolite III; $\triangle$, metabolite IV. IU, integration units of the chromatographic signals. Underlying curves are only intended to visualize the respective trends.

\section{DISCUSSION}

\section{Fluoranthene metabolites and degradation pathways}

In contrast to bacterial pyrene degradation, where only one degradative metabolic route is known to date (Rehmann et al., 1998), there seem to exist at least three bacterial pathways for fluoranthene utilization (see Fig. 1). For Alcaligenes denitrificans Weißenfels et al. (1990) proposed an initial attack at the 7,8-position of the benzylic moiety of the fluoranthene skeleton (Fig. 1, left column), which after ring opening between positions $6 \mathrm{~b}$ and 7 yields the two metabolic intermediates observed: 
1-acenaphthenone and subsequently 3-hydroxymethylbenzo[d,e]chromen-2-one (designated as 7-acenaphthenone and 3-hydroxymethyl-4,5-benzocoumarin by the authors). Naphthalene-1,8-dicarboxylic acid as a fluoranthene metabolite of Sphingomonas paucimobilis EPA505 (formerly classified as Pseudomonas paucimobilis) was described by Mueller et al. (1990, and unpublished results), and ascribed to the metabolic pathway proposed by Weißenfels et al. (1990). For Mycobacterium sp. strain PYR1 and Pasteurella sp. strain IFA Kelley et al. (1993) and Sepic et al. (1998) deduced two different primary dioxygenation sites from the metabolites identified: the 7,8-position according to the former authors from the formation of 1 acenaphthenone, and the 1,2-position in the naphthoic substructure of the fluoranthene molecule due to the occurrence of 1-carboxy-9-hydroxyfluorene, 1-carboxyfluoren-9-one, 9-hydroxyfluorene and fluorene-9-one (Fig. 1 middle column). The late fluoranthene degradation products observed by these authors, namely 2carboxybenzaldehyde, phthalic acid, phenylacetic acid, benzoic acid and adipic acid, could not be unequivocally linked to one of preceding metabolites. However, neither the cis-7,8-fluoranthene dihydrodiol nor the cis-1,2fluoranthene dihydrodiol postulated as initial metabolites by Weißenfels et al. (1990), Kelley et al. (1993) and Sepic et al. (1998) have yet been detected, thus leaving a crucial gap in the proposed pathways.

The five fluoranthene metabolites identified from cultures of Mycobacterium sp. strain KR20 supported a degradation route (Fig. 3, right column) previously outlined by Rehmann et al. (1999). Fluoranthene metabolism by this isolate obviously seems to start with a dioxygenation of the fluoranthene molecule in the 2,3-position, yielding cis-2,3-fluoranthene dihydrodiol (metabolite V). The follow-up product expected, 2,3dihydroxyfluoranthene, could not, however, be detected. But this also holds for the analogous ortho-dihydroxy PAH derivatives in the degradation pathways of anthracene (Fernley et al., 1964) and pyrene (DeanRoss \& Cerniglia, 1996; Heitkamp et al., 1988; Rehmann et al., 1998; Walter et al., 1991), probably due to a strong association of the dihydroxy metabolites with the enzymes involved in their turnover. The ortho ring cleavage of 2,3-dihydroxyfluoranthene leads to the formation of metabolite IV, which subsequently probably loses a $\mathrm{C}_{2}$-unit, hypothetically producing 1carboxyfluorene-9-one. This compound, in contrast to its successor, metabolite II, could not be detected in cultures of strain KR20.

The consequence of this hypothesis is that strain KR20, Mycobacterium sp. strain PYR 1 (Kelley et al., 1993) and Pasteurella sp. IFA (Sepic et al., 1998) might use homologous entry reactions for fluoranthene degradation, implying that the initial dioxygenation by the latter strains also takes place in the 2,3-position. However, the final aromatic metabolites identified by Kelley et al. (1993) and Sepic et al. (1998) suggest a divergence of the metabolic routes in a later stage of degradation, i.e. the breakdown of the fluorene scaffold.
Metabolite II in turn represents the substrate for the second ring-opening reaction, which might proceed by two alternative mechanisms: either by a dehydrogenation of the secondary hydroxy group at C-1 resulting in the formation of a spontaneously hydrolysing 1,3-diketone whose hydrolysis product under acidic conditions (as prevailing during metabolite cleanup) should easily dehydrate to yield the corresponding $\delta$-lactone (Grifoll et al., 1994), or by a biological BaeyerVilliger reaction as suggested for the fluoranthene degradation pathway proposed by Weißenfels et al. (1990). However, the resulting product, metabolite III, after hydrolysis is most likely metabolized analogously to biphenyl (Higson, 1992), since the formation of metabolite I (hemimellitic acid), which represented the last detectable aromatic intermediate, requires the opening of the hydroxylated ring of metabolite III in a biphenyl-like manner. The fate of metabolite I is unclear at the moment and warrants further investigation.

This fluoranthene degradation pathway seems also to be operative in Mycobacterium hodleri inasmuch as Kleespies et al. (1996) reported cis-2,3-fluoranthene dihydrodiol as the only identifiable metabolite (without any structural proof) and the UV-Vis spectra of two other fluoranthene metabolites of this isolate were identical to the UV-Vis spectra of Mycobacterium sp. KR20 metabolites III and IV, respectively (H. Kneifel, personal communication).

The degradative route outlined closely corresponds to a fluorene degradation pathway discovered in a Pseudomonas sp. by Grifoll et al. (1994). Starting with the second dihydrodiol metabolite (metabolite II) of the fluoranthene degradation pathway of strain KR20, characterized intermediates of both pathways are homologues: metabolite II versus cis-1,9a-dihydroxy-1hydrofluorene-9-one, metabolite III versus 4-hydroxybenzo[c]chromene-6-one, and metabolite I versus phthalic acid. The fluoranthene descendants differ from their respective fluorene counterparts each by one additional carboxy group in one of the aromatic rings. This homology might point to an evolutionary relation between the two sets of degradative enzymes, but, as already mentioned, strain KR20 was not able to utilize fluorene as a growth substrate. The reason for the latter observation might be based on the requirement of the dioxygenase involved in the formation of the angular dihydrodiol of an activated carbon atom on position 9 as given when attacking fluoren-9-one (Bressler \& Fedorak, 2000). However, this hypothesis still has to be investigated.

The fact that isolate KR20 did not produce any fluoranthene metabolite attributable to the 'acenaphthenone' route of fluoranthene degradation present in the strains investigated by Kelley et al. (1993), Sepic et al. (1998), Weißenfels et al. (1990) and J. G. Mueller, S. E. Lantz \& C. E. Cerniglia (unpublished results) in our opinion might be related to the inability of $\mathrm{Myco-}$ bacterium sp. strain KR20 to use any other PAH as growth substrate, but this question also requires more detailed investigations. 
Table 7. Utilization of PAH as sole growth substrates by currently known fluoranthene-utilizing (bold) and fluoranthene-degrading bacteria

\begin{tabular}{|c|c|c|c|c|c|c|c|}
\hline \multirow[t]{2}{*}{ Isolate } & \multicolumn{6}{|c|}{ PAH as sole growth substrate*: } & \multirow[t]{2}{*}{ Reference } \\
\hline & NAP & ANT & PHE & FLU & PYR & CRY & \\
\hline \multicolumn{8}{|l|}{ NOCARDIOFORMS } \\
\hline Mycobacterium sp. KR20 & - & - & - & - & - & - & This work \\
\hline Mycobacterium gilvum $\mathrm{BB} 1$ & o & o & + & - & + & o & Boldrin et al. (1993); Böttger et al. (1997) \\
\hline Mycobacterium sp. PY & o & o & + & o & + & o & Bryniok (1994) \\
\hline Mycobacterium sp. PY18 & o & o & + & o & + & o & Bryniok (1994) \\
\hline Mycobacterium flavescens & o & o & + & - & + & o & Dean-Ross \& Cerniglia (1996) \\
\hline Mycobacterium austroafricanum PYR-1 & + & + & + & o & + & o & Kelley et al. (1993); Böttger et al. (1997) \\
\hline Mycobacterium sp. VF1 & + & + & + & o & + & - & Kästner et al. (1994) \\
\hline Mycobacterium hodleri & o & - & - & - & - & o & Kleespies et al. (1996); Böttger et al. (1997) \\
\hline Mycobacterium sp. G4 & o & o & + & + & + & o & Lloyd-Jones \& Hunter (1997) \\
\hline Mycobacterium sp. $\mathrm{O} 1$ & o & o & - & - & - & o & Lloyd-Jones \& Hunter (1997) \\
\hline Mycobacterium sp. Fan 9 & o & o & o & o & $\mathrm{o}$ & o & Willumsen et al. (1998) \\
\hline Rhodococcus sp. SPyrNal & o & o & + & - & + & o & Bouchez et al. (1995) \\
\hline Rhodococcus sp. SFltNal & o & o & + & - & + & o & Bouchez et al. (1995) \\
\hline Rhodococcus sp. UW1 & o & + & + & - & + & + & Walter et al. (1991) \\
\hline Gordona sp. BP9 & + & - & + & $\mathrm{o}$ & + & - & Kästner et al. (1994) \\
\hline Coryneform SAntMu3 & o & + & + & - & + & o & Bouchez et al. (1995) \\
\hline \multicolumn{8}{|l|}{ NON-NOCARDIOFORMS } \\
\hline Pseudomonas sp. K12 & + & + & + & o & + & o & Thibault et al. (1996) \\
\hline Pseudomonas putida $\mathrm{Ph61}$ & o & o & + & o & + & o & Bryniok (1994) \\
\hline Pseudomonas aeruginosa AK1 & o & o & + & o & + & o & Bryniok (1994) \\
\hline Sphingomonas paucimobilis EPA505† & + & + & + & - & - & - & Mueller et al. (1990) \\
\hline Sphingomonas sp. FLA 1-1‡ & o & o & + & o & o & o & Ho et al. (2000) \\
\hline Sphingomonas sp. FLA 4-1 $\neq$ & o & o & - & o & o & o & Ho et al. (2000) \\
\hline Sphingomonas sp. FLA 6-1 & o & o & + & o & o & o & Ho et al. (2000) \\
\hline Sphingomonas sp. CO6 $\ddagger$ & o & o & + & + & o & o & Ho et al. (2000) \\
\hline Sphingomonas yanoikuyae 107 & o & o & $\mathrm{o}$ & o & + & o & Dagher et al. (1997) \\
\hline Xanthomonas maltophilia N3F2 & o & o & o & o & o & o & Mueller et al. (1997) \\
\hline Pasteurella sp. IFA & o & o & o & o & o & o & Sepic et al. (1998) \\
\hline Burkbolderia cepacia VUN 10001\| & o & o & + & + & + & o & Juhasz et al. (1997) \\
\hline Alcaligenes denitrificans WW1 & + & + & + & - & - & - & Weißenfels et al. (1990) \\
\hline
\end{tabular}

*Abbreviations: NAP, naphthalene; ANT, anthracene; PHE, phenanthrene; FLU, fluorene; PYR, pyrene; CRY, chrysene. Symbols: + , growth; - , no growth; o, no data published.

† Originally classified as Pseudomonas pancimobilis EPA505.

$\ddagger$ Representatively selected from a total of 27 Gram-negative fluoranthene degraders described with 11 strains identified as Sphingomonas sp.

\Eight fluoranthene degraders were isolated; only one gave conclusive results in classification.

$\|$ One out of three very similar strains described.

\section{Time course of fluoranthene degradation}

Strain KR20 pre-grown on fluoranthene degraded the same compound in batch cultures without any apparent lag phase, thereby increasing its cell number about 30-fold within 10-14 d and excreting limited amounts of the metabolites reported above. As mentioned, the situation with non-fluoranthene-grown inocula was different. The temporary accumulation of cis-2,3fluoranthene dihydrodiol observed in this case might be caused by an induction event, i.e. the dihydrodiol accumulated only until the degradation pathway enzymes were fully induced. A comparable transient accumulation of primary dihydrodiol metabolites was reported for the degradation of phenanthrene and pyrene by Mycobacterium sp. strain KR2 (Rehmann et al., 1996, 1998).

Since under any conditions, none of the metabolites accumulated in a $1: 1$ stoichiometric ratio to the amount of fluoranthene added, it may be assumed that no real dead-end metabolites (in the sense of being not substrates for any degradative enzyme of the strain) were produced. Rather, the amount of degradation products 
found might be interpreted as spillover of the cells due to the large amount of growth substrate available or compounds which cannot be reassimilated, e.g. due to their ionic character.

\section{Fluoranthene-degrading bacteria}

Mycobacterium sp. strain KR20 represents one of about 50 bacterial fluoranthene degraders described during recent years (Table 7). Currently the number of Gramnegative isolates, especially Sphingomonas sp., matches or even outnumbers the number of Gram-positive fluoranthene-utilizing bacteria (Mueller et al., 1997; Ho et al., 2000). This finding is in contrast to the situation with pyrene-degrading bacteria, where nocardioforms (Gram-positives) constitute the majority of species described so far (Ho et al., 2000; Kästner et al., 1994; Rehmann et al., 1998), a fact that was ascribed to the facilitated interaction of hydrophobic PAH with the outer cell surface of Gram-positive bacteria, which is also hydrophobic in nature (Rehmann et al., 1998). However, it is still open to discussion (Mueller et al., 1997) to what extent the enrichment techniques used bias the ratio depicted in Table 7. For example, Bastiaens et al. (2000) demonstrated that the type of fluoranthene degrader isolated from the same soil sample was clearly dependent on the kind of enrichment technique applied, whereas Mueller et al. (1997), in several cases, obtained similar spectra of fluoranthene-degrading organisms despite applying different kinds of enrichment procedures to the same soil sample.

Another interesting aspect arising from Table 7 is that the fluoranthene degraders seem to form two clusters with respect to their PAH-utilization capabilities. One set, containing most of the organisms studied, encompasses strains capable of utilizing at least two or more of the three- and four-ring PAHs as a sole source of carbon and energy (which appears to be quite common among PAH-degrading bacteria). In contrast, the members of the second set, Mycobacterium sp. strain KR20 (Rehmann et al., 1999; this work), Mycobacterium hodleri (Kleespies et al., 1996), Mycobacterium sp. strain O1 (Lloyd-Jones \& Hunter, 1997) and Sphingomonas sp. strain FLA 6-1 (Ho et al., 2000) appear to be unable to use any other PAH besides fluoranthene as a sole growth substrate. Restrictions concerning the PAHutilization pattern of bacteria were also observed by other authors but seemed to be associated with the bacterial type (Gram-positive or Gram-negative) or genera investigated (Ho et al., 2000; Kästner et al., 1994; Mueller et al., 1997). The reason for the substrate specificity of these Gram-positive and Gram-negative strains deserves further investigation.

\section{ACKNOWLEDGEMENTS}

We wish to thank Mr A. Papaderos for the preparative cleanup of some of the metabolites, Ms L. Lattmann and $\mathrm{Mr}$ S. Achatz for performing the GC-MS and HPLC-MS measurements, respectively, and Dr. J. G. Mueller (Dames \& Moore, Chicago, USA) and Professor H. Kneifel (ICG 6,
Forschungszentrum Jülich) for additional information and helpful discussions.

\section{REFERENCES}

Babson, J. R., Russo-Rodruiguez, S. E., Wattley, R. V., Bergstein, P. L., Rastetter, W. H., Liber, H. L., Andon, B. M., Thilly, W. G. \& Wogan, G. N. (1986). Microsomal activation of fluoranthene to mutagenic metabolites. Toxicol Appl Pharm 85, 355-366.

Bastiaens, L., Springael, D., Wattiau, P., Harms, H., deWachter, R., Verachtert, H. \& Diels, L. (2000). Isolation of adherent polycyclic aromatic hydrocarbon (PAH)-degrading bacteria using $\mathrm{PAH}-$ sorbing carriers. Appl Environ Microbiol 66, 1834-1843.

Boldrin, B., Thiem, A. \& Fritsche, C. (1993). Degradation of phenanthrene, fluorene, fluoranthene, and pyrene by a Mycobacterium sp. Appl Environ Microbiol 59, 1927-1930.

Böttger, E. C., Kirschner, P., Springer, B. \& Zumft, W. (1997). Mycobacteria degrading polycyclic aromatic hydrocarbons. Int $J$ Syst Bacteriol 47, 247.

Bouchez, M., Blanchet, D. \& Vandecasteele, J.-P. (1995). Degradation of polycyclic aromatic hydrocarbons by pure strains and by defined strain associations: inhibition phenomena and cometabolism. Appl Microbiol Biotechnol 43, 156-164.

Bressler, D. C. \& Fedorak, P. M. (2000). Bacterial metabolism of fluorene, dibenzofurane, dibenzothiophene, and carbazole. Can J Microbiol 46, 397-403.

Bryniok, D. (1994). PAK-Abbau in Mehrphasensystemen. In Biologischer Abbau von polycyclischen aromatischen Koblenwasserstoffen, pp. 91-108. Edited by B. Weigert. Berlin: SFB 193 der TU Berlin.

Dagher, F., Deziel, E., Lirette, P., Paquette, G., Bisaillon, J.-G. \& Villemur, R. (1997). Comparative study of five polycyclic aromatic hydrocarbon degrading bacterial strains isolated from contaminated soils. Can J Microbiol 46, 368-377.

Dean-Ross, D. \& Cerniglia, C. E. (1996). Degradation of pyrene by Mycobacterium flavescens. Appl Microbiol Biotechnol 46, 307-312.

Edwards, N. T. (1983). Polycyclic aromatic hydrocarbons (PAH's) in the terrestial environment - a review. J Environ Qual 12, $427-441$.

Fernley, H. N., Griffiths, E. \& Evans, W. C. (1964). Oxidative metabolism of phenanthrene and anthracene by soil bacteria: the initial ring-fission step. Biochem J 91, 15p-16p.

Grifoll, M., Selifonov, S. A. \& Chapman, P. J. (1994). Evidence for a novel pathway in the degradation of fluorene by Pseudomonas sp. strain F274. Appl Environ Microbiol 60, 2438-2449.

Harvey, R. G. (1991). Polycyclic Aromatic Hydrocarbons: Chemistry and Carcinogenicity. New York, Port Chester, Melbourne, Sydney: Cambridge University Press.

Heitkamp, M. A., Franklin, W. \& Cerniglia, C. E. (1988). Microbial metabolism of polycyclic aromatic hydrocarbons: isolation and characterization of a pyrene-degrading bacterium. Appl Environ Microbiol 54, 2549-2555.

Higson, F. (1992). Microbial degradation of biphenyl and its derivatives. Adv Appl Microbiol 37, 135-164.

Ho, Y., Jackson, M., Yang, Y., Mueller, J. G. \& Pritchard, P. H. (2000). Characterization of fluoranthene- and pyrene-degrading bacteria isolated from PAH-contaminated soils and sediments. J Ind Microbiol Biotechnol 24, 100-112.

Jeffrey, A. M., Yeh, H. J. C., Jerina, D. M., Patel, T. R., Davey, J. F. \& Gibson, D. T. (1975). Initial reactions in the oxidation of naphthalene by Pseudomonas putida. Biochemistry 14, 575-584. 
Jerina, D. M., Selander, H., Yagi, H., Wells, M. C., Davey, J. F., Mahadevan, V. \& Gibson, D. T. (1976). Dihydrodiols from anthracene and phenanthrene. J Am Chem Soc 98, 5988-5996.

Juhasz, A. L., Britz, M. L. \& Stanley, G. A. (1997). Degradation of fluoranthene, pyrene, benz[a]anthracene and dibenz[a,h]anthracene by Burkholderia cepacia. J Appl Microbiol 83, 189-198.

Kanaly, R. A. \& Harayama, S. (2000). Biodegradation of highmolecular-weight polycyclic aromatic hydrocarbons by bacteria. J Bacteriol 182, 2059-2067.

Kästner, M., Breuer-Jammali, M. \& Mahro, B. (1994). Enumeration and characterization of the soil microflora from hydrocarboncontaminated soil sites able to mineralize polycyclic aromatic hydrocarbons (PAH). Appl Microbiol Biotechnol 41, 267-273.

Kelley, I., Freeman, J., Evans, F. E. \& Cerniglia, C. E. (1993). Identification of metabolites from the degradation of fluoranthene by Mycobacterium sp. strain PYR-1. Appl Environ Microbiol 59, 800-806.

Kiyohara, H., Nagao, K. \& Yana, K. (1982). Rapid screen for bacteria degrading water-insoluble, solid hydrocarbons on agar plates. Appl Environ Microbiol 43, 454-457.

Kleespies, M., Kroppenstedt, R. M., Rainey, F. A., Webb, L. E. \& Stackebrandt, E. (1996). Mycobacterium hodleri, sp. nov., a new member of the fast-growing mycobacteria capable of degrading polycyclic aromatic hydrocarbons. Int J Syst Bacteriol 46, 683-687.

Lloyd-Jones, G. \& Hunter, D. W. F. (1997). Characterization of fluoranthene- and pyrene-degrading Mycobacterium-like strains by RAPD and SSU sequencing. FEMS Microbiol Lett 153, 51-56.

Minnikin, D. E., Alshamaony, L. \& Goodfellow, M. (1975). Differentiation of Mycobacterium, Nocardia, and related taxa by thin-layer chromatographic analysis of whole-organism methanolysates. J Gen Microbiol 88, 200-204.

Mueller, J. G., Chapman, P. J., Blattmann, B. O. \& Pritchard, P. H. (1990). Isolation and characterization of a fluoranthene-utilizing strain of Pseudomonas paucimobilis. Appl Environ Microbiol 56, 1079-1086.

Mueller, J. G., Devereux, R., Santavy, D. L., Lantz, S. E., Willis, S. G. \& Pritchard, P. H. (1997). Phylogenetic and physiological comparison of PAH-degrading bacteria from geographically diverse soils. Antonie Leeuwenhoek 71, 329-343.

Pothuluri, J. V., Heflich, R. H., Fu, P. P. \& Cerniglia, C. E. (1992). Fungal metabolism and detoxification of fluoranthene. Appl Environ Microbiol 58, 937-941.

Reasoner, D. J. \& Geldreich, E. E. (1985). A new medium for the enumeration and subculture of bacteria from potable water. Appl Environ Microbiol 49, 1-7.

Rehmann, K., Steinberg, C. E. W. \& Kettrup, A. A. (1996). Branched metabolic pathway for phenanthrene degradation in a pyrene-degrading bacterium. Polycycl Aromat Comp 11, 125-130.

Rehmann, K., Noll, H. P., Steinberg, C. E. W. \& Kettrup, A. A. (1998). Pyrene degradation by Mycobacterium sp. strain KR2. Chemosphere 36, 2977-2992.

Rehmann, K., Hertkorn, N. \& Kettrup, A. A. (1999). Bacterial fluoranthene degradation - indication for a novel degradation pathway. In Novel Approaches for Bioremediation of Organic Pollution; Proceedings of the 42nd Oholo Conference Eilat, Israel (3.5-7.5.1998), pp. 39-46. Edited by R. Fass, Y. Flashner \& S. Reuveny. New York, Boston, Dordrecht, London, Moscow: Kluwer Academic/Plenum.

Rice, J. E., LaVoie, E. J. \& Hoffmann, D. (1983). Synthesis of the isomeric phenols and the trans-2,3-dihydrodiol of fluoranthene. J Org Chem 48, 2360-2363.

Selifonov, S. A., Grifoll, M., Gurst, J. E. \& Chapman, P. J. (1993). Isolation and characterization of $(+)-1,1$-dihydroxy-1hydroxyfluoren-9-one formed by angular dioxygenation in the bacterial catabolism of fluorene. Biochem Biophys Res Commun 193, 67-76.

Sepic, E. \& Leskovsek, H. (1999). Isolation and identification of fluoranthene biodegradation products. Analyst 124, 1765-1769.

Sepic, E., Bricelj, M. \& Leskovsek, H. (1998). Degradation of fluoranthene by Pasteurella sp. IFA and Mycobacterium sp. PYR1: isolation and identification of metabolites. J Appl Microbiol 85, 746-754.

Suess, M. J. (1976). The environmental load and cycle of polycyclic aromatic hydrocarbons. Sci Total Environ 6, 239-250.

Sutherland, J. B., Rafii, F., Khan, A. A. \& Cerniglia, C. E. (1995). Mechanisms of polycyclic aromatic hydrocarbon degradation. In Microbial Transformation and Degradation of Toxic Organic Chemicals, pp. 269-306. Edited by L. Y. Young \& C. E. Cerniglia. New York, Chichester, Brisbane, Toronto, Singapore: Wiley-Liss.

Thibault, S. L., Anderson, M. \& Frankenberger, W. T., Jr (1996). Influence of surfactants on pyrene desorption and degradation in soils. Appl Environ Microbiol 61, 283-287.

Thomas, A. O. \& Lester, J. N. (1993). The microbial remediation of former gasworks sites: a review. Environ Technol 14, 1-24.

Thomas, A. O. \& Lester, J. N. (1994). The reclamation of disused gaswork sites: new solutions to an old problem. Sci Total Environ 152, 239-260.

Walter, U., Beyer, M., Klein, J. \& Rehm, H.-J. (1991). Degradation of pyrene by Rhodococcus sp. UW1. Appl Microbiol Biotechnol 34, 671-676.

Wayne, L. G., Engbœk, C., Engel, H. B. W. \& 17 other authors (1974). Highly reproducible techniques for use in systematic bacteriology in the genus Mycobacterium: tests for pigment, urease, resistance to sodium chloride, hydrolysis of Tween 80, and $\beta$-galactosidase. Int J Syst Bacteriol 24, 412-419.

Weißenfels, W. D., Beyer, M. \& Klein, J. (1990). Degradation of phenanthrene, fluorene and fluoranthene by pure bacterial cultures. Appl Microbiol Biotechnol 32, 479-484.

Willumsen, P. A., Karlson, U. \& Prichard, P. H. (1998). Response of fluoranthene-degrading bacteria to surfactants. Appl Microbiol Biotechnol 50, 475-483.

Zink, G. \& Lorber, K. E. (1995). Mass spectral identification of metabolites formed by microbial degradation of polycyclic aromatic hydrocarbons (PAH). Chemosphere 31, 4077-4084.

Received 2 March 2001; revised 30 May 2001; accepted 8 June 2001. 